\title{
CARACTERIZAÇÃO MORFOMÉTRICA DA BACIA HIDROGRÁFICA DO RIO URUPUCA, MINAS GERAIS, BRASIL
}

\author{
Cláudia Laís Rodrigues Barreto-claudialaisrb@ gmail.com \\ Universidade Estadual do Sudoeste da Bahia \\ Maxwell Christian Silva Canaverde Oliveira-maxwell_dm@ hotmail.com \\ Universidade Estadual do Sudoeste da Bahia
}




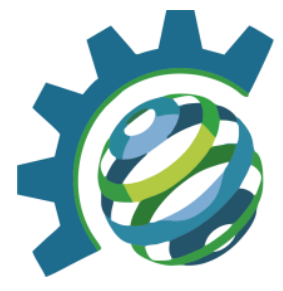

\section{RESUMO}

O presente estudo teve como objetivo determinar as características morfométricas da bacia hidrográfica do rio Urupuca, Minas Gerais, Brasil, utilizando o Sistema de Informações Geográficas (SIG). A área de drenagem encontrada na bacia foi de 2333,148 km², perímetro de $294,531 \mathrm{~km}$, comprimento total da rede de drenagem foi de $652,878 \mathrm{Km}$, coeficiente de compacidade de 1,7073, fator de forma 0,346. A densidade de drenagem encontrada na bacia hidrográfica do rio Urupuca foi de $0,279451 \mathrm{~km} / \mathrm{km}^{2}$, sendo considerada uma bacia com drenagem pobre. Diante da análise dos resultados obtidos, concluiu-se que a bacia em estudo não tem tendência de transbordar, sendo mais alongada e baixa susceptibilidade a infiltração de água no solo.

Palavras-chave: Bacia hidrográfica, morfometria, drenagem.

\section{INTRODUÇÃO/OBJETIVO}

De acordo com a Lei Federal 9.433/97, a bacia hidrográfica é a unidade de implementação de gestão de recursos hídricos. De acordo com Silveira (2001), bacia hidrográfica é definida como uma área de captação natural da precipitação que faz convergir os escoamentos para um único ponto de saída, o exutório, sendo composta basicamente de um conjunto de superfícies vertentes e de uma rede de drenagem formada por cursos d'água que confluem até resultar em um leito único no exutório.

O comportamento hidrológico de uma bacia hidrográfica é função de suas características geomorfológicas, como forma, relevo, área, geologia, rede de drenagem, solo, etc., bem como do tipo da cobertura vegetal existente (LIMA, 1986). Portanto, as características físicas e bióticas de uma bacia possuem importante papel nos processos do ciclo hidrológico, influenciando a infiltração, a quantidade de água produzida como deflúvio, a evapotranspiração, os escoamentos superficial e sub-superficial, dentre outros. Além disso, o comportamento hidrológico de uma bacia hidrográfica também é afetado pelas ações antrópicas, uma vez que, ao intervir no meio natural, o homem acaba interferindo nos processos do ciclo hidrológico.

A caracterização morfométrica de uma bacia hidrográfica consiste na caracterização de parâmetros fisiográficos, que são indicadores físicos da bacia. Esta caracterização tem 

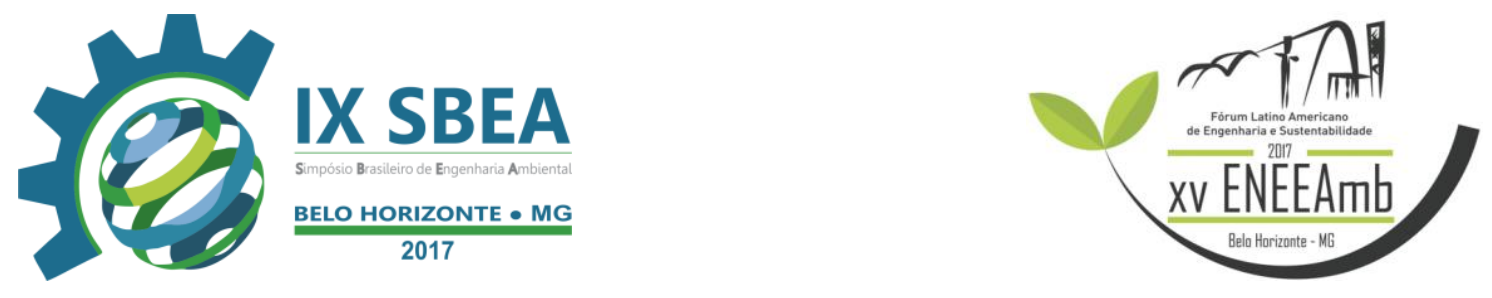

grande aplicação como indicadores para previsão do grau de vulnerabilidade da bacia a fenômenos como enchentes, inundações e erodibilidade (Villela \& Mattos, 1975; Cardoso et al., 2006). Aliada ao conhecimento de componentes da dinâmica de funcionamento do ciclo hidrológico permite avaliar o potencial hídrico de uma região, sendo, portanto instrumentos fundamentais para o manejo de bacias hidrográficas, processo que permite formular um conjunto integrado de ações sobre o meio ambiente, a estrutura social, econômica, institucional e legal de uma bacia, a fim de promover a conservação e utilização sustentável dos recursos naturais, principalmente os recursos hídricos, e o desenvolvimento sustentável (Tonello, 2005).

A delimitação de uma bacia hidrográfica é um dos primeiros e mais comuns procedimentos executados em análises hidrológicas ou ambientais, as informações associadas à uma região podem ser preparadas e analisadas no processo de modelagem. Os Sistemas de Informações Geográficas (SIGs) vem sendo amplamente usados para essa finalidade. Os SIGs constituem conjuntos interativos de subsistemas orientados à organização da informação espacial com o objetivo de subministrar elementos de apoio à tomada de decisões.

Diante do exposto, o presente trabalho torna-se uma ferramenta para a gestão de recursos hídricos no estado de Minas Gerais, onde se caracterizou morfometricamente a bacia do rio Urupuca, a partir de alguns parâmetros tais como: área de drenagem da bacia, perímetro, comprimento total da rede de drenagem, coeficiente de compacidade(Kc), fator de forma(Kf), relevo, densidade de drenagem e ordem dos cursos d'água.

\section{METODOLOGIA}

\subsection{Descrição da área de estudo}

A área-base deste estudo abrange a bacia hidrográfica do rio Suaçui Grande, com área total de 22,632 $\mathrm{Km}^{2}$, pertencente à bacia hidrográfica do rio Doce. O rio Urupuca é encontrado nesta bacia hidrográfica sendo localizada na região leste do estado de Minas Gerais (Figura 1) e está compreendida entre as coordenadas geográficas 1759' S-17,99611 e 18¹9' S-18,32444, abrangendo parte dos municípios de Água boa, São José da Safira, Malacaheta, Itambacuri, Marilac e Franciscópolis (Figura 2). Sedimentos quaternários 

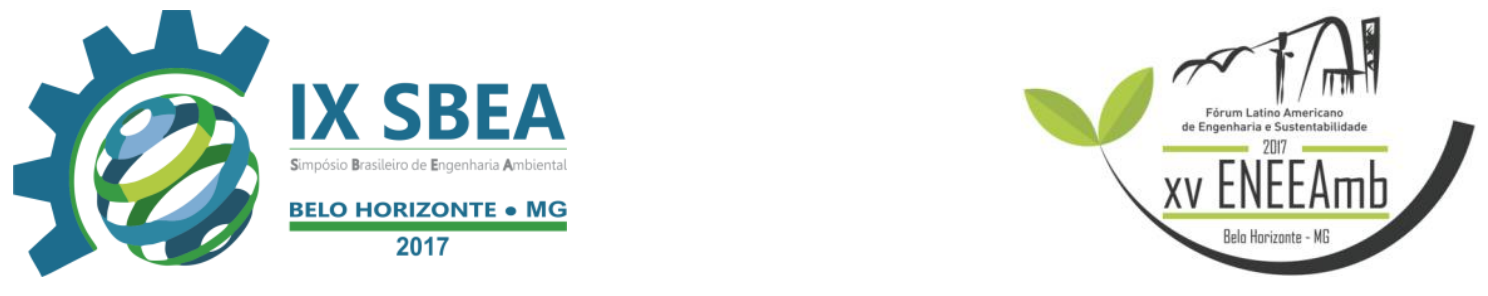

ocorrem ao longo dos vales, constituindo depósitos aluvionares de caráter argiloso,argiloarenoso ou arenoso, representados por terraços e leitos maiores de deposição mais recente (REZENDE, 1971; RADAMBRASIL, 1983; CORRÊA, 1984). O clima da região possui inverno seco e verão chuvoso, com temperatura do mês mais frio inferior a $18^{\circ} \mathrm{C}$ e, do mês mais quente, superior a $22^{\circ} \mathrm{C}$ (BARUQUI, 1982).

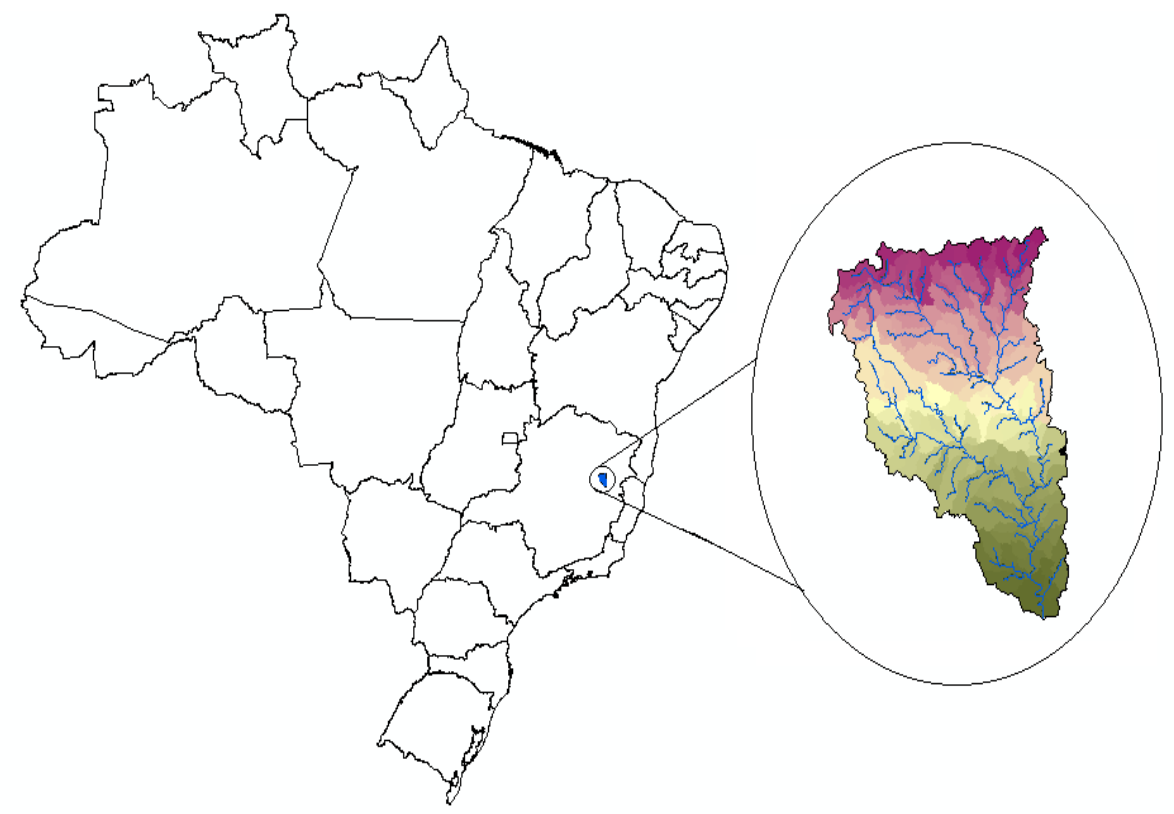

Figura 1. Bacia do rio Urupuca 

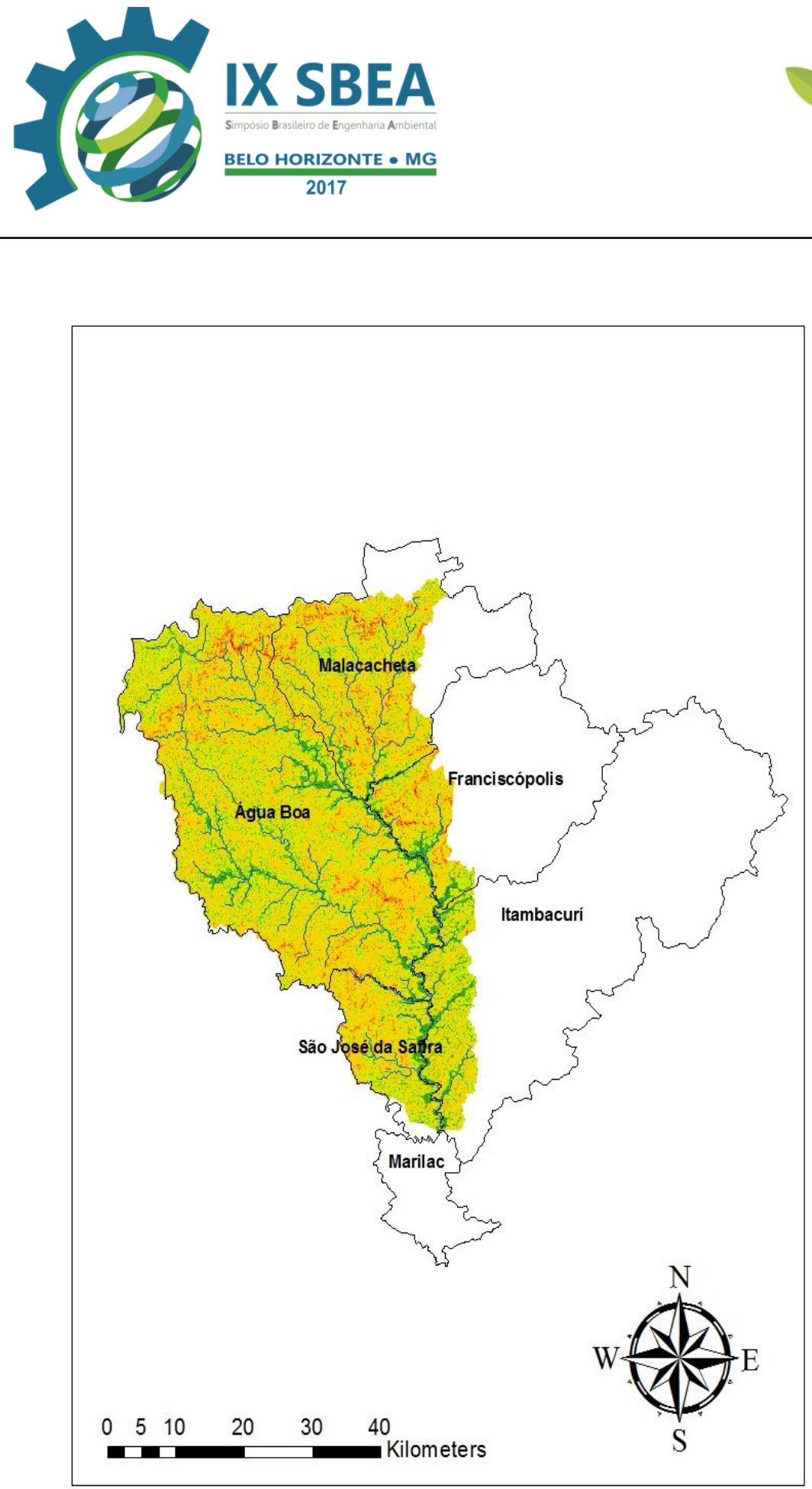

Figura 2. Cidades banhadas pela bacia do rio Urupuca.

3.2 Caracterização morfométrica da bacia hidrográfica

\subsubsection{Modelo Digital de Elevação (MDE)}

A bacia delimitada não é a reprodução igual da bacia real. Com isso, o software ArcGIS oferece ferramentas para que as inconsistências presentes na bacia gerada sejam sanadas. Os processos descritos a seguir foram de suma importância para evitar possíveis problemas que impossibilitariam os estudos hidrológicos da bacia. No ArcMAP utilizou-se o 


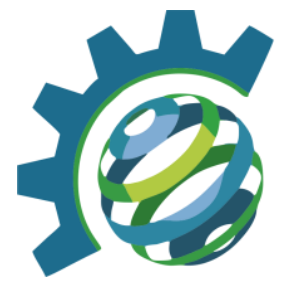

algoritmo Thin (AS) para afinar a hidrografia criada a um valor escolhido, diminuindo o número de pixels que representam uma feição.

Para realização da pesquisa, foi necessário a utilização de um software chamado ArcGis. Inicialmente foi criado um modelo digital de elevação. No site da Embrapa (http://www.relevobr.cnpm.embrapa.br/download/index.htm) há disponível a imagem SRTM (que são disponibilizadas com a extensão correspondente às das cartas do IBGE na escala 1:250000) de todo o país, bastando apenas localizar a carta referente à zona onde o rio se encontra, que neste caso foram duas: SE-23-X-D e SE-23-Z-B (figura 3).

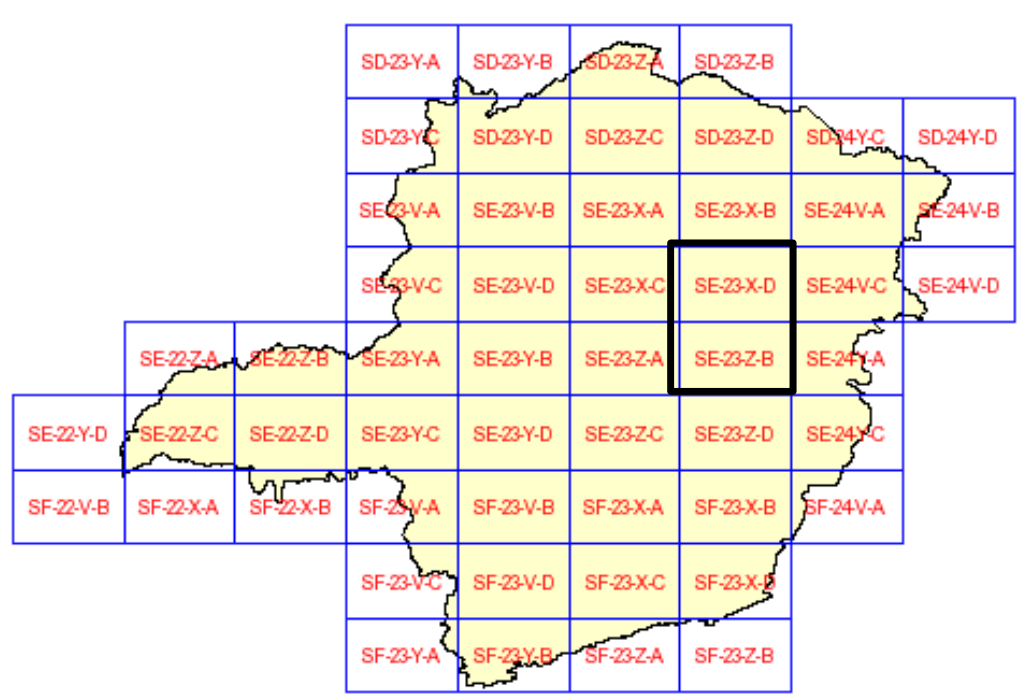

Figura 3. Zonas utilizadas da carta: SE-23-X-D e SE-23-Z-B.

Uma vez baixada as cartas, uniu-as em um só arquivo através do ArcGis para melhor operação, criando um mosaico. Com a carta devidamente configurada, foram eliminadas as depressões espúrias, ou seja, células cercadas por outras com maiores valores de elevação, remanescentes ou que foram introduzidas no MDE durante o processo de imposição da rede de drenagem, que atrapalham a análise de direção do escoamento.

Com a direção de escoamento devidamente configurada, foi feito a acumulação de escoamento, através da ferramenta Flow accumulation. Em seguida fez-se a drenagem numérica, onde os rios e suas nascentes são gerados por acúmulo de células. Para finalizar a criação do modelo, criou-se um arquivo tipo shape no formato point feature, e foi estabelecido no exutório, para identificar a foz. Em seguida, utilizou-se o comando watershare para delinear toda a bacia que compreende o rio Urupuca. 


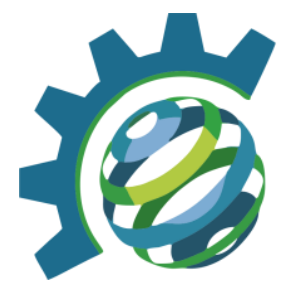

\subsubsection{Morfometria da Bacia Hidrográfica}

Para finalizar a caracterização da bacia, resta apenas definir as propriedades morfométricas da mesma, obtidas também através do ArcMap. Com a delimitação da área da bacia em posse, obtiveram-se diferentes características físicas, como: área da bacia, perímetro, comprimento total da rede de drenagem, coeficiente de compacidade, fator de forma, relevo, densidade de drenagem e ordem dos cursos d'água.

Inicialmente converteu-se o arquivo raster da bacia em polígono, ativando a simplificação de polígonos, pois dessa forma o contorno da bacia é suavizado, aumentando a proximidade com a real feição da bacia. Esse passo é importante no cálculo de algumas propriedades, como o perímetro, que pode ser superestimado caso não haja a simplificação. Para delimitação do perímetro e área de drenagem, foi necessário apenas a utilização da ferramenta Calculate geometry, criando antes duas novas coluna de dados na tabela de atributos do polígono da bacia, uma com o nome de área e outra de perímetro.

Para obtenção do comprimento total da rede de drenagem utilizou-se primeiramente a ferramenta stream to feature, para designar a fluxo total da bacia. Em seguida, na tabela de conteúdo, foi acessado a opção Statistics, o somatório de segmentos de fluxo, obtendo assim o comprimento total de drenagem.Com a ferramenta Stream Link, foi possível determinar as seções do rio conectadas por duas confluências, uma confluência e um foz, ou uma nascente a uma conlfuência. Feito isso, pôde-se então indicar as sub-bacias de contribuição, através da ferramenta Watershed presente dentro da caixa de ferramenta Spartialanalist tools/ Hidrology.

A densidade de drenagem foi obtida utilizando Field Calculator. O fator de forma e o coeficiente de compacidade foram obtidos utilizando as mesmas ferramentas usadas na obtenção da densidade, determinando, para cada propriedade, sua respectiva expressão algébrica. Por conseguinte, obteve-se o mapa de declividade da bacia, utilizando a ferramenta Slope, presente dentro da caixa de ferramentas Spartial analist tools/Surface. O próprio programa divide a declividade por cores, dando intervalos a cada cor. Para melhor adequação, configurou-se a declividade de acordo com os intervalos da Embrapa. 


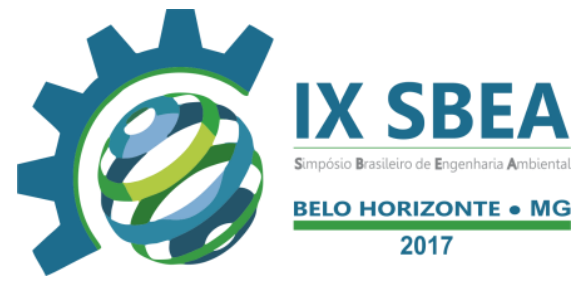

\section{RESULTADOS E DISCUSSÃO}

O resumo das características físicas calculadas para a bacia rio Urupuca/MG é apresentado na Tabela 1

Tabela 1. Característica físicas da bacia do Rio Urupuca

\begin{tabular}{|c|c|}
\hline CARACTERÍSTICAS FÍSICAS & RESULTADOS \\
\hline Ordem da bacia & 4 \\
\hline Área de drenagem $\left(\mathrm{Km}^{2}\right)$ & 2333,148 \\
\hline Perímetro $(\mathrm{Km})$ & 294,531 \\
\hline Comprimento total da rede de & 652,878 \\
\hline drenagem $(\mathrm{Km})$ & 1,7073 \\
\hline Coeficiente de compacidade $(\mathrm{Kc})$ & 0,346 \\
\hline Fator de forma $(\mathrm{Kf})$ & 0,279451 \\
\hline Densidade de drenagem $\left(\mathrm{km} / \mathrm{km}^{2}\right)$ & \\
\hline
\end{tabular}

A área de drenagem encontrada na bacia foi de 2333,148 $\mathrm{km}^{2}$ o seu perímetro, de $294,531 \mathrm{~km}$ e o comprimento total da rede de drenagem foi de 652,878 Km. De acordo com os resultados, pode-se afirmar que a bacia hidrográfica do rio Urupuca mostra-se pouco suscetível a enchentes pelo fato de o coeficiente de compacidade apresentar o valor de 1,7073 sendo consideravelmente distante do valor unitário e, quanto ao seu fator de forma 0,346 apresentar-se um valor muito abaixo de um. Vê-se pelos números citados que a bacia em estudo tem tendência de não possuir uma forma circular, sendo mais alongada.

A densidade de drenagem encontrada na bacia hidrográfica do rio Urupuca foi de 0 , $279451 \mathrm{~km} / \mathrm{km}^{2}$, sendo considerada uma bacia com drenagem pobre. O sistema de drenagem da bacia em estudo, de acordo com a hierarquia de Strahler, possui ramificação de quarta ordem. 

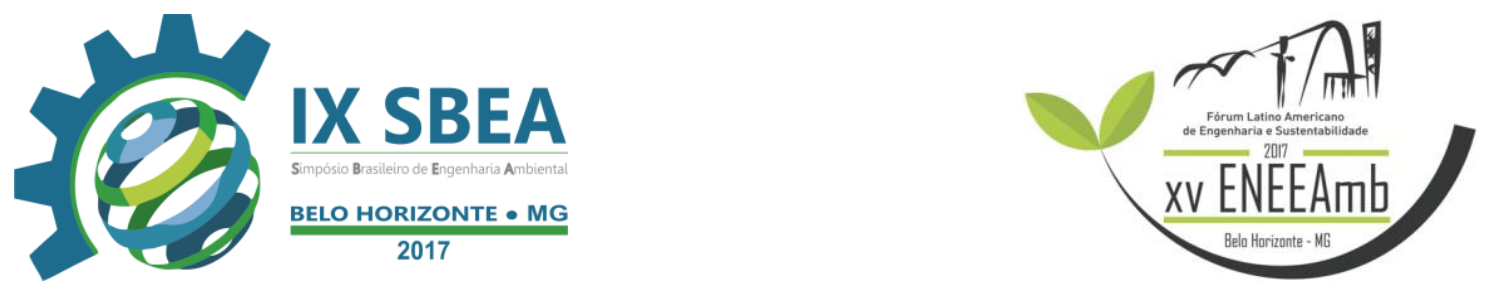

$\mathrm{Na}$ figura 4, apresentam-se as informações quantitativas associadas ao relevo do terreno da bacia. Observa-se, nesse quadro, que a maior parte do relevo corresponde ao ondulado e ao fortemente ondulado. A declividade influencia a relação sobretudo devido ao aumento da velocidade de escoamento superficial, reduzindo a possibilidade da infiltração de água no solo. Observando a figura 4, pode-se ver de forma mais clara a declividade da bacia, classificando o relevo com os mesmos intervalos delimitados pela Empraba. Nota-se que é uma região com poucas áreas montanhosas.

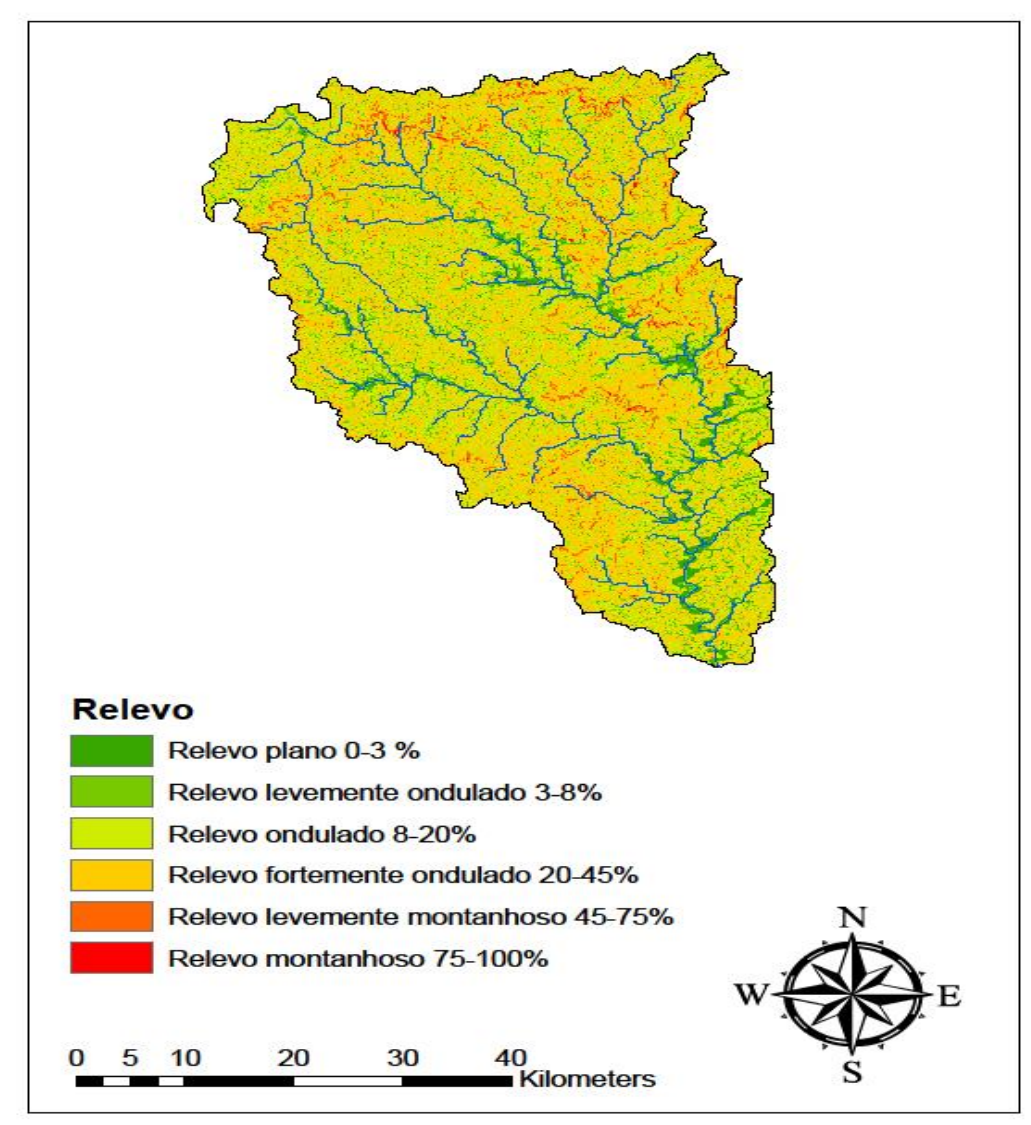

Figura 4. Relevo da Bacia do Rio Urupuca

\section{CONCLUSÕES/RECOMENDAÇÕES}

As propriedades geomorfológicas citadas nesse artigo são os principais fatores para caracterização de uma bacia hidrográfica. $\mathrm{O}$ fato de possuir um coeficiente de compacidade alto indica que a bacia tem formato irregular, logo dificilmente estará sujeita a inundações. A 

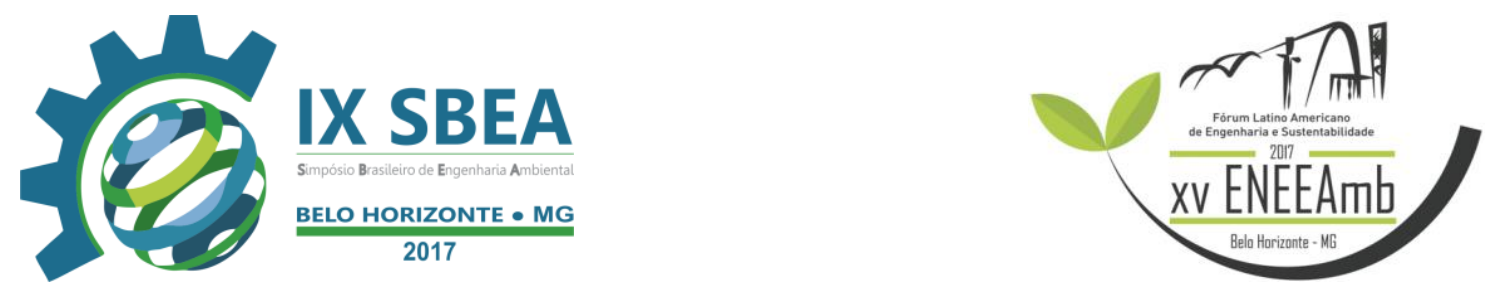

mesma conclusão pode ser obtida através do fator de forma, que por possuir um valor muito baixo, indica baixa probabilidade de enchentes. Isso se deve ao fato que quanto mais irregular a bacia hidrográfica, maior será o tempo de concentração (tempo que leva para a água sair do ponto mais remoto e chegar na foz). Outra informação muito importante é a ordem da bacia. Como a bacia estudada possui ordem 4, pode-se inferir que o rio Urupuca não possui confluências com grandes rios, e apresenta uma largura de porte médio

Aliado à ferramenta ArcGis, foi possível estabelecer os critérios fisiográficos da bacia do rio Urupuca de forma prática e com margem de erro minimizadas.

\section{REFERÊNCIAS BIBLIOGRÁFICAS}

BARUQUI, F.M. Inter-relações solo-pastagens nas regiões da Mata e Rio Doce do Estado de Minas Gerais. Viçosa: UFV, 1982. 119P. Dissertação (Mestrado em solos e nutrição de plantas)- Universidade Federal de Viçosa, 1982.

CARDOSO, C.A.; DIAS, H.C.T.; SOARES, C.P.B.; MARTINS, S.V. Caracterização morfométrica da bacia hidrográfica do rio Debossan, Nova Friburgo, RJ. Revista Árvore, v. 30, n. 2, p. 241-248, 2006.

CORRÊA, G. F. Modelo de evolução e mineralogia da fração argila de solos do planalto de Viçosa, MG. Viçosa, M.G.: UFV, 1984. 86p. Dissertação (Mestrado em Solos e Nutrição de Plantas)- Universidade Federal de Viçosa, 1984

LIMA, W. P. Princípios de hidrologia florestal para o manejo de bacias hidrográficas. Piracicaba; ESALQ/USP,1986, 282p.

RADAMBRASIL. Levantamento de recursos naturais: Folhas 23/24. Rio de Janeiro/Vitória. Rio de Janeiro: 1983. V 32, 767p.

REZENDE, S. B. Estudo da crono-topossequência em Viçosa-Minas Gerais. Viçosa: UFV, 1971. 71p. Dissertação (Mestrado em Fitotecnia)- Universidade Federal de Viçosa, 1971.

SILVEIRA, A.L.L. Ciclo hidrológico e bacia hidrográfica. In: TUCCI, C.E.M. (Org.). Hidrologia: ciência e aplicação. São Paulo: EDUSP, 2001. p 35-51.

TONELLO, K.C. Análise Hidroambiental da Bacia Hidrográfica da Cachoeira das Pombas, Guanhães, MG. Viçosa, 2005. 69 p. Dissertação (Mestrado em Ciências Florestais) - Universidade Federal de Viçosa.

VILLELA, S.M. \& MATTOS, A. Hidrologia aplicada. São Paulo: McGraw-Hill do Brasil, 245 p., 1975. 